\title{
O PROCESSO DE DECISÃO DO CONSUMIDOR DA EDUCAÇÃO EAD: O CASO DO CENTRO UNIVERSITÁRIO DO NORTE DO PARANÁ
}

\author{
MARINGÁ/PR JULHO/2018
}

\author{
Victor Vinicius Biazon - UniCesumar - victorbiazon@hotmail.com \\ Ednilson Barbosa de Oliveira - UniCesumar - ednilsonbo@gmail.com \\ Cecilia Adriana da Silva - UniCesumar - cecilia.silva@unicesumar.edu.b \\ Renata Ramos Pavan Terra - UniCesumar - renata.terra@unicesumar.edu.br \\ Wainer Cristiano Cancian - UniCesumar - wainercristian@gmail.com \\ Simone Oliveira dos Santos Cardoso - UniCesumar - admsimonecardoso@gmail.com \\ Fernando Alberto Jorgeto - UniCesumar - fernandojorgeto@gmail.com \\ Deivison Augusto dos Santos Domingues - UniCesumar - deivison.domingues@unicesumar.edu.br
}

Tipo: Investigação Científica (IC)

Natureza: Relatório Final de Pesquisa

Categoria: Pesquisa e Avaliação

Setor Educacional: EDUCAÇÃO SUPERIOR

\begin{abstract}
RESUMO
O presente trabalho buscou conhecer o processo individual de decisão dos alunos EaD de uma instituição de ensino superior (IES), localizada no Norte do estado do Paraná a partir de modelo "processo de decisão de compra", a fim de tornar possivel a elaboração de um perfil. Como método, desenhou-se como descritiva e bibliográfica, com coleta de dados quantitativa a partir de questionário eletrônico disseminado dentro da estrutura de projeto da IES cuja amostra (não representativa) somou 386 participações de 16 estados do Brasil, que permitiu identificar, que a necessidade do consumo de serviços educacionais foi iniciada por questões de mercado, de busca de qualificação, e a partir disso buscaram informações em sua maioria online, mas foram considerados grupos de referência (off-line). Metodologia flexível de ensino, a modalidade de tecnologia pela duração do curso e o status da IES foram determinantes para a escolha dos respondentes que estão realmente satisfeitos com a escolha $e$ que apenas deixariam (descartariam) esse consumo por problemas financeiros ou por problemas relacionados à equipe pedagógica.
\end{abstract}

Palavras-chave: Decisão; Consumidor; EAD; Perfil. 


\section{INTRODUÇÃo}

No acelerado ritmo do novo milênio as organizações perceberam a necessidade de fornecer produtos e serviços que além de atender, devem superar as expectativas dos clientes. Foi-se o tempo em que o comportamento do consumidor era visto como um processo simplificado de interação entre produtores e compradores no ato da compra, o chamado "comportamento do comprador". O processo de troca previsto nas publicações de Marketing não se limita a entrega de mercadoria por um valor monetário, esta é sim, uma parte importante dentro do comportamento do consumidor, mas, ainda há questões que "influenciam o consumidor antes, durante e depois da compra" (SOLOMON, 2011, p. 34). Neste cenário, quando as instituições de ensino superior (IES), sobretudo privadas, quando planejam seus processos seletivos (vestibular) precisam ter em mente que é seu público de interesse e se comunicar com ele de forma inteligente. Pensando neste aspecto, o presente trabalho buscou conhecer o processo individual de decisão de compra dos alunos matriculados na modalidade de Educação à distância (EaD) de uma IES localizada no Norte do estado do Paraná a partir do modelo proposto por Blackwell et al. (2009), conhecido como processo de decisão de compra, a fim de tornar possível a elaboração de um perfil. A pesquisa se justifica, pois, possibilita o conhecimento das formas pelas quais os alunos fizeram a comparação entre outras IES que oferecem cursos na modalidade EaD e quais foram os critérios considerados decisivos no momento da escolha da IES objeto do estudo, possibilitando assim, elaborar novas estratégias de retenção de alunos, assim como identificar os fatores considerados pontos positivos nesta escolha, permitindo também ampliar suas formas de contato, possibilitando uma melhora nos pontos negativos apontados pelo aluno.

\section{FATORES INFLUENCIADORES DE ESCOLHA E PROCESSO DE DECISÃO DO CONSUMIDOR}

O estudo do comportamento do consumidor é um processo longo e abrangente conforme explica Solomon (2011, p. 33) dizendo que "é o estudo dos processos envolvidos quando indivíduos ou grupos selecionam, compram, usam ou descartam produtos e serviços, ideias ou experiências para satisfazer desejos e necessidades". Segundo Karsaklian (2009, p. 13), o comportamento do consumidor é apenas uma parte do ser humano, com suas motivações e busca de determinadas ambições para a realização pessoal. "Ninguém compra um produto a não ser que haja um problema, uma necessidade ou um desejo" (BLACKWELL, MINIARD E ENGEL, 2008, p. 6-73). É necessário estar atento a diversos fatores que influenciam diretamente o comportamento de compra, por exemplo, os culturais; pessoais como idade, condição econômica e cargo; psicológicos como motivação, personalidade, e percepção e social como grupos de referência (ENGEL; BLACKWELL; MINIARD, 2000; CHURCHILL; PETER, 2000; SCHIFFMAN, KANUK, 2000; SOLOMON, 2002; KOTLER, KELLER, 2007). Na literatura 
de marketing diversos autores já tentaram formatar um "esquema" padrão de como os consumidores executam o processo de decisão. Mas, de acordo com o ensaio de Faria (1983), para Weber os sentidos das ações humanas não podem ser captados, mas propõe o chamado "Tipos ideais" que fazem menção ao primeiro nível de generalização de conceitos. Estes tipos ideais estão alicerçados a outro conceito denominado "conceitos limites" ligado ao conceito das imagens sobre as quais as relações são construídas sendo possível expor o rumo que tomaria uma ação social particular caso envolvesse o mesmo fim. Segundo Luppe e Angelo (2010) as pesquisas em julgamento e tomada de decisão têm como foco o modo como as pessoas combinam desejos e crenças na escolha de um curso de ação. Para Blackwell, et al.. (2008), a tomada de decisão de compra do consumidor passa por sete processos conforme figura 1 :

Figura 1: Processo em que os consumidores tomam decisões para bens e serviços

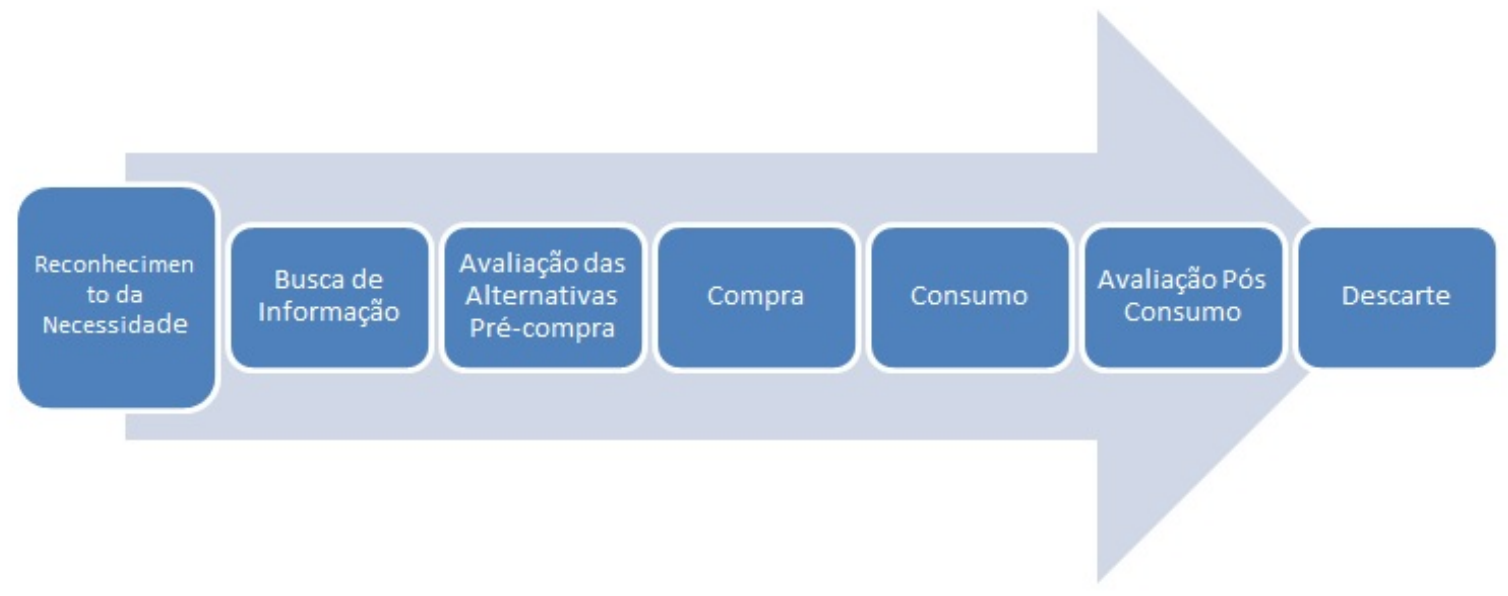

Fonte: Blackwell et al. (2009, p. 73)

No Reconhecimento da necessidade: Ocorre sempre que o consumidor percebe uma diferença significativa entre o seu estado atual e algum estado desejado ou ideal. Há um problema a ser resolvido; Busca de informações: É o processo pelo qual o consumidor realiza pesquisas (interna e externamente) a procura de dados adequados para tomar uma decisão razoável; Avaliação das alternativas pré-compra: Quando o consumidor julga cada uma das alternativas levantadas em termos de caracteristicas e atributos. Cada consumidor tem uma forma singular de perceber os atributos antes de decidir pela compra; Compra: O consumidor reduziu as alternativas a uma e fez sua escolha; Consumo e Avaliação Pós-consumo: Durante e depois do consumo, os indivíduos acabam desenvolvendo sensação de satisfação, ou não com a compra; Descarte: corre quando o consumidor não utiliza mais o bem ou serviço. Estas etapas acontecem sequencialmente como um processo de decisão que pode ser rápido ou mais moroso 
dependendo do grau de envolvimento ou discernimento do consumidor.

\section{PROCEDIMENTOS METODOLÓGICOS}

Trata-se de uma pesquisa descritiva com finalidade de analisar o comportamento de compra dos alunos de uma instituição de ensino superior na modalidade de educação a distância $(\mathrm{EaD})$, quanto aos fatores de decisão com relação à sua escolha pela instituição, considerando o processo de decisão e compra do consumidor proposto por Blackwell et al. (2009). Quanto aos procedimentos técnicos, optou-se pela pesquisa bibliográfica buscando embasamento teórico para o estudo em questão. Do ponto de vista da forma de abordagem ao problema, utilizou-se de pesquisa qualitativa a fim de levantar dados necessários para a investigação. Os dados primários foram coletados por meio da ferramenta Google forms (drive), disponibilizada via ambiente virtual aos alunos como parte integrante de um projeto de ensino. Primeiramente o acesso foi liberado aos alunos dos cursos de Marketing, Gestão Comercial e Gestão de Lojas e Pontos de Venda, e posteriormente para outros cursos (por adesão) no qual foi considerado como período de resposta os dias 10 a 20 de outubro de 2017 sendo obtidas 386 respostas como amostra originadas de todas as regiões do Brasil, sendo 16 estados, a saber: MT; PR; SC; MG; RO; ES; RS, PE; RJ; PA; TO; AL; SP; MA; DF; BA.

\section{APRESENTAÇÃO E ANÁLISE DOS RESULTADOS}

No gráfico 1 estão dispostos os percentuais referentes à faixa etária do público da pesquisa, observando nesta etapa, aspectos socioeconômicos.

Gráfico 1 - faixa etária

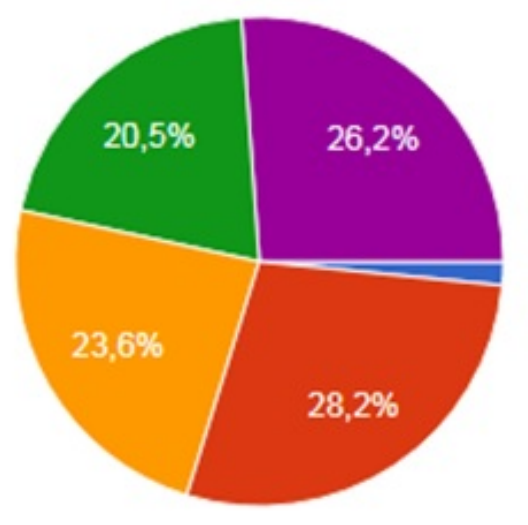

Fonte: Dados da pesquisa 
A soma dos percentuais, dos respondentes que têm idade entre 19 e 25 anos, e entre 26 e 32 anos, totaliza $51,8 \%$ do total do público entrevistado, demonstrando que o público predominante para a aquisição de cursos superiores na modalidade à distância concentrou-se entre jovens adultos. Quanto ao gênero, verificou-se um público feminino responsável por $49,5 \%$ das respostas obtidas, e o público masculino, composto por $50,5 \%$. Percebeu-se ainda que que concluíram o ensino médio há mais de sete anos são predominantes e $77,5 \%$ dos entrevistados terminaram o ensino médio em escolas públicas. Sobre o estado civil dos entrevistados, a pesquisa apontou que a maioria $(52,1 \%)$, são casados ou moram juntos com seus companheiros e 53,9\% não têm filhos, seguidos daqueles que têm pelo menos 1 filho $(23,1 \%)$. Em relação à renda familiar, aqueles que totalizam até $R \$ 2.000,00 /$ mês e aqueles que totalizam de $R \$ 2.001,00$ a $R \$ 4.000,00$, representam $72,8 \%$ dos respondentes, e $78 \%$ disseram que exercem alguma atividade remunerada em tempo integral. Quando indagados sobre os meios utilizados para pagamento dos estudos, conforme disposto no gráfico 2 , a maior parte dos entrevistados $75,9 \%$ respondeu que utiliza de recursos próprios. Poucos recebem ajuda de familiares ou possuem bolsas de estudos, por exemplo, da empresa, o que confirma as respostas obtidas acima Esta etapa da pesquisa contribuiu para delinear os traços socioeconômicos do público abordado, onde se pode observar aspectos como a condição social e econômica dos respondentes, algo relevante para a compreensão do contexto deste público.

Gráfico 2 - pagamento do curso superior

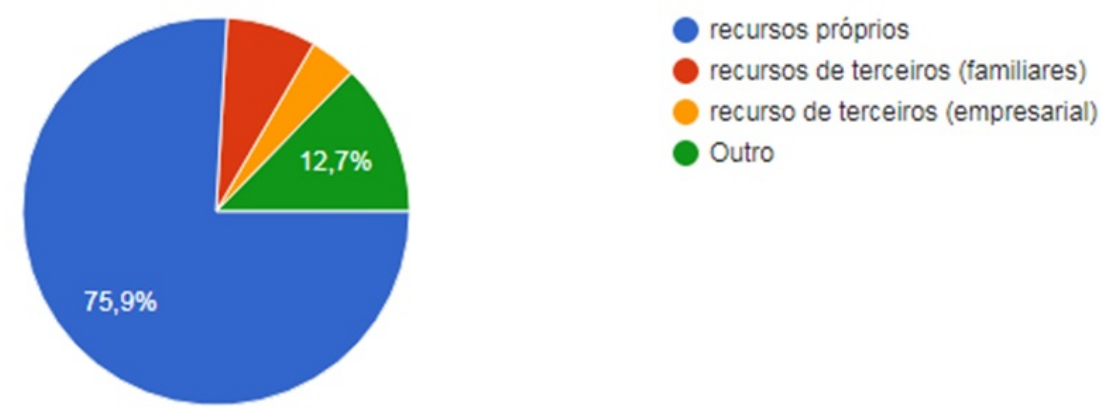

Fonte: Dados da pesquisa

A partir de agora será abordada a etapa na qual foram analisados os fatores influenciadores. Assim, o gráfico 3 que trata das diferenças pessoais, apresenta quais motivos os alunos consideram na escolha para ingressar em um curso superior. Os itens ocupação e circunstâncias pessoais são os mais importantes (representando 80,1\%), uma vez que a fase ou etapa da vida (que corresponde a 19,9\%) não atingiu um índice 
muito representativo, o que evidencia a preocupação com as exigências do mercado.

Gráfico 3: diferenças pessoais

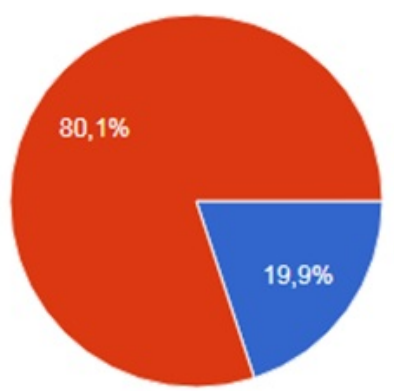

Fonte: dados da pesquisa.

Já quanto aos processos psicológicos,conforme gráfico 4, que demonstra a influência para ingresso no ensino superior, $52,3 \%$ dos entrevistados apontaram que o motivo que os levou a ingressar no curso superior, foi a possibilidade de formação pessoal e profissional, que se relaciona às expectativas do aluno em relação às exigências do mercado e da sociedade, bem como aos valores e crenças que o aluno possui.

Gráfico 4 - processos psicológicos

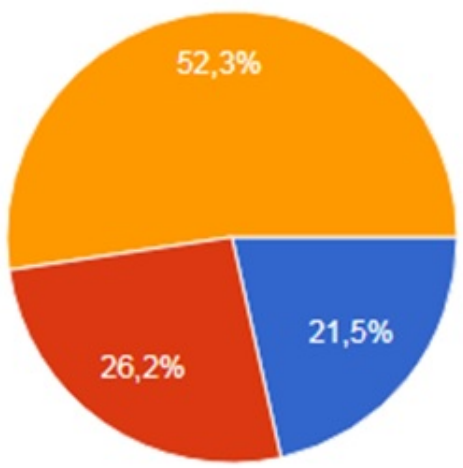

querer adquirir conhecimento;

percepção de que é necessário ter formação superior;

minha formação pessoal e

profissional faz parte de quem eu sou ou quero ser

Fonte: dados da pesquisa.

Um dos pontos que merecem atenção nesse estudo é o fato de apenas $21,5 \%$ dos alunos terem respondido que realizam o curso superior porque desejam adquirir conhecimento. Esse dado reflete a preocupação que as instituições devem ter com a formação dos alunos, sobretudo com aqueles que já atuam profissionalmente na área do 
curso e que pensam já possuírem o conhecimento necessário para exercício da profissão, buscando apenas a formalização documental, para comprovação do conhecimento sobre a área. No item influenciadores externos, gráfico 5, a maioria dos entrevistados $(24,4 \%)$ sinalizou que o fato do trabalho exigir formação superior, foi responsável por decidir cursar a faculdade.

Gráfico 5 - influenciadores externos

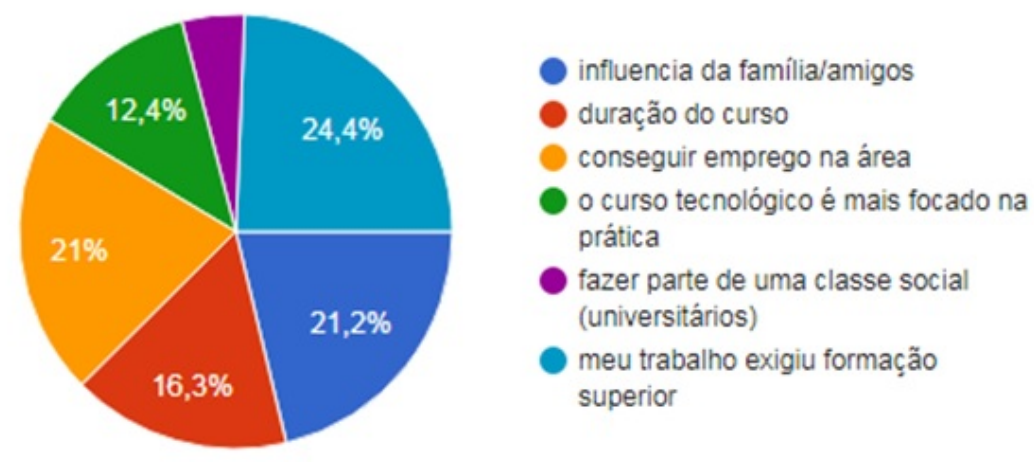

Fonte: dados da pesquisa.

Em análise ao motivo que os levou a optar pelo curso no qual estão matriculados, identificou-se que a maioria, 63,2\% dos entrevistados, respondeu que trata-se de interesse pessoal pela profissão, o que está ligado a um influenciador pessoal superando fatores externos e psicológicos. Quanto aos resultados específicos do processo de decisão de escolha dos respondentes pela IES, verificou-se por etapa que o reconhecimento da necessidade (etapa 1) se deu pela busca por qualificação pessoal foi o item de maior resposta, dada pelos entrevistados, quando perguntado sobre como percebeu a necessidade de fazer uma faculdade. A busca de informação (etapa 2) aconteceu $55,7 \%$ das vezes nas mídias sociais/internet seguido de influenciadores sociais como amigos e conhecidos (32,4\%). Na etapa 3, avaliação das alternativas (disposto no gráfico 6), 49\% dos respondentes optaram em fazer uma faculdade a distância pela IES objeto deste estudo devido às metodologias de ensino. O que leva a reflexão de que as aulas ao vivo e os outros atributos da IES é uma das vantagens competitivas. Outras opções destacadas pelos alunos foram consideradas conforme 0 gráfico 6, a seguir:

Gráfico 6 - Avaliação das alternativas 


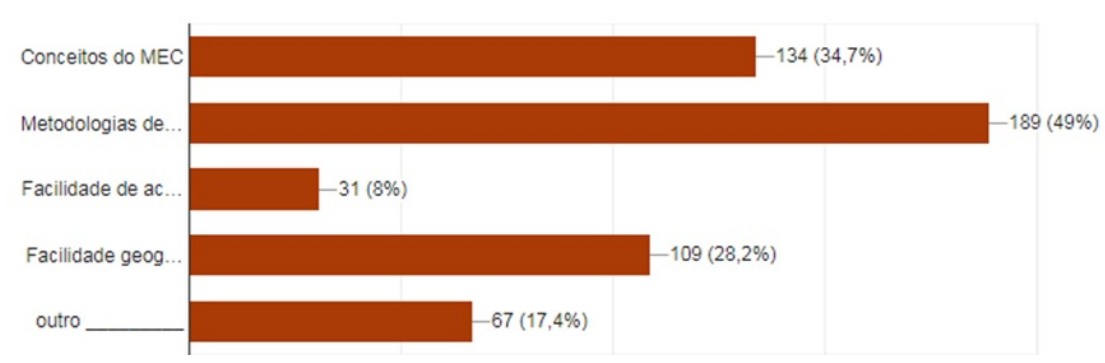

Fonte: dados da pesquisa.

Os motivos que levaram os entrevistados a escolherem a instituição pesquisada (etapa 4, compra), destaca-se a escolha pelo curso em si e duração; conceito do MEC; pelo status de se estudar na instituição em questão; pela localização; e outro motivo importante, que diz respeito ao preço, conforme observados no gráfico 7 .

Gráfico 7 - Etapa de compra: seleção da IES
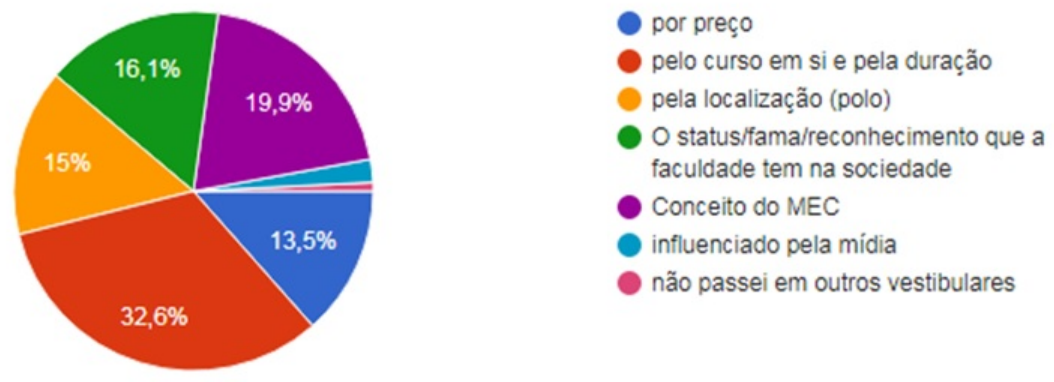

Fonte: dados da pesquisa

Nas etapas 5 e 6 que se referem a experiência de consumo e sua avaliação póscompra, percebe-se que $80,3 \%$ estão satisfeitos ou muito satisfeito com a escolha que fizeram, ou seja, com os serviços educacionais prestados pela instituição. $\mathrm{Na}$ etapa 7 , de descarte, percebeu-se que questões relacionadas aos problemas financeiros destacaram-se como resposta de maior percentual. O questionamento envolvido diz respeito ao que os faria trancar a matrícula na IES. Outro item relevante e que merece atenção das IES é o fatos dos alunos destacarem que trancariam o curso caso houvesse insatisfação com os professores. A equipe pedagógica é o coração do curso e um dos elementos essenciais para a boa formação dos alunos. Por isso, é importante que as IES fiquem atentas quanto à problemas diretos ou avaliações dos alunos sobre a equipe de professores do curso. Conforme gráfico 8: 


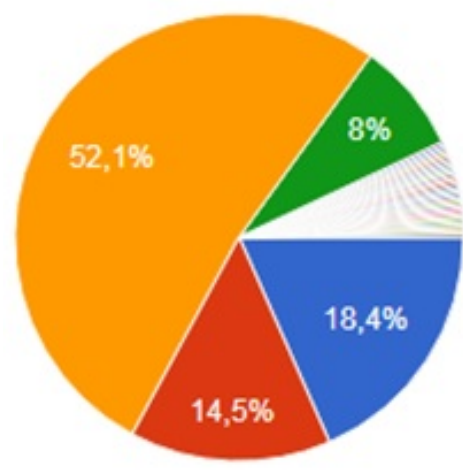

insatisfação com professores/media.

insatisfação com metodologia de en.

problemas financeiros

oferta de melhores condições em 0 .

Se não mantiverem o ensino propo.

qualquer impossibilidade

a falta de considerações de atividad.

Insatisfação com os conteúdos tran.

Fonte: dados da pesquisa

Contudo, apesar de alguns entrevistados não indicarem interesse na realização de uma pós-graduação, a grande maioria, 96,6\% sinalizam que estariam dispostos a continuar os seus estudos na instituição.

\section{CONSIDERAÇÕES FINAIS}

Quanto ao perfil, os alunos são homens e mulheres com faixa etária heterogênea, em sua maioria, casados sem filhos que pagam pelos próprios estudos e talvez por isso buscam a modalidade $\mathrm{EaD}$, por questões de flexibilidade, tempo e recurso. São influenciados pelo mercado, pela profissão, pelo que são ou querem ser e por isso buscam formação específica. A necessidade do consumo da educação foi iniciada por questões de mercado e busca de qualificação. Fatores como metodologia flexível de ensino, a modalidade (cursos de tecnologia), duração do curso e o status da IEs, foram determinantes para a escolha. Há satisfação com o consumo e apenas haveria descarte por problemas financeiros ou com a própria metodologia. Entender como ocorre a decisão dos alunos que já fazem parte da IES podem ajudar a captar novos ingressantes, conhecendo as expectativas em relação ao curso e os motivos que os levaram a efetuar a procura de informações.

\section{REFERÊNCIAS}

BLACKWELL, Roger D; ENGEL, James F; MINIARD, Paul W. Comportamento do consumidor. São Paulo: Cengage Learning, 2008.

BOONE, Louis E.; KURTZ, David L. Marketing Contemporâneo. São Paulo: Cengage Learning, 2009.

CHURCHILL, Gilbert A; PETER, Paul. Marketing: Criando valor para os clientes. São Paulo: Saraiva, 2008. 
COUTINHO, Fernanda Gabriela de Andrade; DOMINGUES, Deivison Augusto dos

Santos. Comportamento do consumidor. Maringá: UNICESUMAR, 2016.

FARIA, José Henrique. Weber e a sociologia das organizações. Revista de Administração - Volume 18(2) abril/junho-83. Páginas 23 a 29. Disponível em Similares> Acesso em 25 ago 2017.

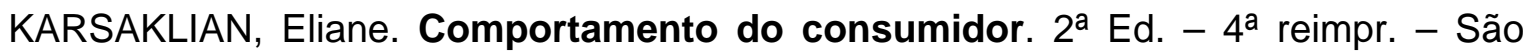
Paulo: Atlas, 2009.

KOTLER, Philip.; KELLER, Kevin Lane. Administração de Marketing.12.ed. São Paulo: Pearson Prentice Hall, 2007.

SCHIFFMAN, Leon G.; KANUK, Leslie Lazar. Comportamento do consumidor. $6^{\underline{a}}$ Ed. Rio de Janeiro: LTR, 2000.

SOLOMON, Michael R. O comportamento do consumidor: comprando, possuindo e sendo. $7^{\text {a }}$ Ed. - Porto Alegre: Bookman, 2008.

O comportamento do consumidor: comprando, possuindo e sendo. Tradução Luiz Claudio de Queiroz Faria. 9.ed. Porto Alegre: Bookman, 2011. 